\title{
Methods for the Determination of the Heat Transfer Coefficient in Air Cooled Condenser Used at Biomass Power Plants
}

\author{
Yanán Camaraza-Medina \\ Technical Sciences Faculty, Universidad de Matanzas, Matanzas 44440, Cuba
}

Corresponding Author Email: yanan.camaraza@umcc.cu

https://doi.org/10.18280/ijht.390505

Received: 9 October 2019

Accepted: 11 October 2020

\section{Keywords:}

flow condensation, heat transfer coefficient, mathematical deduction

\begin{abstract}
In the present work, its show a summary of functional relationships developed for the application of dry condensation systems to Biomass Power Plants that present difficulties with access to water for condensation. The bibliographic review reveals the limitations of the analyzed works, in terms of the development of mathematical models and empirical correlations that allow evaluating the simultaneous effects of the surrounding meteorological variables on the average coefficient of heat transfer and the effect on the environment of the use of dry condensation. The analytical study is based on the weak solutions and their correlation with experimental quantities available in research already established in the area of action, a procedure is developed for the calculation of the average coefficients of heat transfer that includes the influence of local climatologically variables, the effect of the spatial distribution of the tubes package on the refrigerant and the confined confinement in inclined components, which increase the reliability of the thermo-hydraulic analysis and suppresses the need for the use of excess areas required by current methods. The proposed models and correlations allow the preparation of a procedure, by means of which all the possible operative variants are evaluated.
\end{abstract}

\section{INTRODUCTION}

At the end of 2019, about 32 percent of water withdrawals for industrial purposes were used in wet condensers. In areas with limited access to water, the most widespread solution is the use of dry condensers, which achieve savings rates of water consumption close to 95 percent $[1,2]$.

The Cuban state has planned an investment that will allow the installation of $1650 \mathrm{MW}$ of power, (solar, wind and biomass), which represents 24 percent of the national energy matrix. Of these, $875 \mathrm{MW}$ correspond to 25 Biomass Power Plant (BPP) projects, which require high volumes of water for their condensation system, however, these requirements violate Law 124/2017 on the use of terrestrial waters [3].

Given the downturn of the water deficit and the potentiality of the use of biomass as an energy source, the use of ACC can be an effective solution, however in its evaluation there are inconveniences [4].

ACC uses air as refrigerant, which is why, the installation evidences a low global heat transfer coefficient, besides than the variation of the environmental temperature and the velocity of the wind affect this heat transfer coefficient perceptibly. The vapor condenses in the inside of inclined tubes, however, at the present time, does not count on a procedure that it enables getting from reliable way, the values of the heat transfer coefficients for this type of configuration [5-7].

The methods currently used in the evaluation of the global coefficient $\mathrm{K}$ in an ACC are imprecise, because they do not include the effect of local climatic variables, the influence of the geometry of the tube package on the refrigerant and the condensation confined in inclined components, so the use of excess area is required in the operation of these facilities [813].

For this reason, the main objective of the present work is to define a procedure for the calculation of the average heat transfer coefficients that includes the influence of local climatic variables, the effect of the spatial distribution of the tube package on the refrigerant and the condensation confined in inclined components, which increases the reliability of thermo-hydraulic analysis and eliminates the need to use excess areas required by current methods.

\section{EXTERNAL FLOW}

\subsection{External heat transfer coefficient $\alpha_{L}$}

An analysis of 783 experimental data sets reported in eight specialized papers on the subject, allowed to develop a dimensionally non-homogeneous expression, which was generated by an integral analysis of residues by cross-jump methods at intervals (Breshnetzov method), which correlates with an average error of $\pm 6.9 \%$ in $84.8 \%$ percent of the available experimental samples. This equation is given by the following expression [14]:

$$
\alpha_{L}=\frac{\left(1+\log _{10}\left(T_{T B S} / V_{V}\right)^{0.015}\right) \cdot\left(V_{m}\right)^{0.06}\left(e_{a} \cdot h_{a}\right)^{0.01}}{\left(0.15 \cdot\left(S_{T}-d_{e}\right)^{0.4}\right) \cdot \ln (F)^{0.28}}
$$

where: $\mathrm{S}_{\mathrm{T}}$ is the transverse step, in $\mathrm{m} ; \mathrm{V}_{\mathrm{V}}$ is the velocity of the incident wind on the ACC installation, in $\mathrm{m} / \mathrm{s} ; \mathrm{V}_{\mathrm{m}}$ is the velocity in the narrowest section of the tube package, in $\mathrm{m} / \mathrm{s}$; 
$e_{a}$ is the fins thickness, in $\mathrm{mm}$; $\mathrm{d}_{\mathrm{e}}$ is the outer diameter of the bare tubes (without fins), in $\mathrm{m} ; \mathrm{h}_{\mathrm{a}}$ is the height of the fins, in $\mathrm{mm} ; \mathrm{F}$ is the number of fins per linear meter of finned tube length; $T_{T B S}$ is dry bulb temperature, in ${ }^{\circ} \mathrm{C}$. Value of $\mathrm{V}_{\mathrm{m}}$ is determined by using the following criteria [15]:

$$
\begin{aligned}
& \text { if } \quad 2\left(S_{D}-d_{E}\right)>\left(S_{T}-D\right) \rightarrow V m=\frac{S_{T}}{S_{T}-d_{E}} V_{0} \\
& \text { if } \quad 2\left(S_{D}-d_{E}\right) \leq\left(S_{T}-D\right) \rightarrow V m=\frac{S_{T}}{2\left(S_{D}-d_{E}\right)} V_{0}
\end{aligned}
$$

where: $\mathrm{V}_{0}$ is the rate of entry of the cooling agent into the tube package, in $\mathrm{m} / \mathrm{s} ; \mathrm{S}_{\mathrm{T}}$ is the transverse step, in $\mathrm{m} ; \mathrm{S}_{\mathrm{L}}$ is the longitudinal step, in $\mathrm{m}$; $\mathrm{D}$ is the outer diameter of the tubes + fins, which make up the package, in $\mathrm{m} ; \mathrm{S}_{\mathrm{D}}$ is the diagonal step, in $\mathrm{m}$,

Table 1 gives the validity parameters of Eq. (1), while all the experimental data used in its development and validation are given by Camaraza-Medina et al. [14]

Table 1. Validity range of the Eq. (1)

\begin{tabular}{cccc}
\hline Parameter & Range & Parameter & Range \\
\hline Tube inclination ACC & $45-60^{\circ}$ & $h_{a}(\mathrm{~mm})$ & $2.5-7.9$ \\
$d_{e}(\mathrm{~mm})$ & $19-50$ & $V_{0}(\mathrm{~m} / \mathrm{s})$ & $0.1-100$ \\
$S_{T} / S_{L}$ & $0.4-2$ & $T_{T B S}\left({ }^{\circ} \mathrm{C}\right)$ & $15-43$ \\
$V_{v}(\mathrm{~m} / \mathrm{s})$ & $0-45$ & $e_{a}(\mathrm{~mm})$ & $1.3-3.5$ \\
\hline
\end{tabular}

The deviation is determined by the following expression:

$$
E=100 \cdot\left|\frac{\alpha_{L}-\alpha_{\text {exp }}}{\alpha_{L}}\right|
$$

In Eq. (3) $\alpha_{\exp }$ is the average experimental heat transfer coefficient, while the mean absolute error (MAE) is determined as:

$$
M A E=\frac{1}{N} \sum_{N}\left|\frac{\alpha_{L}-\alpha_{e x p}}{\alpha_{L}}\right|
$$

In Eq. (4), $N$ is the amount of experimental data available. In Tables 2 and 3 the validity range of the Eq. (1) is fragmented in six zones, the average and maximum deviation obtained in its correlation with the available experimental data being given in each case.

In Figures 1 and 2, the values of $M A E$ and $E_{\max }$ obtained in the correlation developed between available experimental data and selected models are given in graphical form [15].

The study shows that in the first and second range, the fundamentals results used in the comparison concentrate on two fundamental elements, described early $\left(M A E\right.$ and $\left.E_{\max }\right)$. In these, it is confirmed that the model given by Camaraza et al. (Eq. (3)) [14] have the best $M A E$ adjustment values, showing an average error of $7.6 \%$ and $7.2 \%$ in the correlation with available experimental data for zones 1 and 6 , respectively.

In the specialized literature it is established that Zukauskas's model correlates with an average error of $25 \%$; however, the results obtained in the present study show an average error of $29.6 \%$ and $32.3 \%$ in the correlation with available experimental data for zones 1 and 6 , respectively, proving that the values obtained in the present study are slightly higher to the values commonly attributed in the literature.

The most unfavorable indicators are obtained using the models of Griminson and Engineering Sciences Data Unit (ESDU), which provide $M A E$ values of $33.2 \%$ and $29.1 \%$ respectively for zone 1 , while the $M A E$ values of $28.2 \%$ and $27.4 \%$ respectively for zone 6 . The models of Gray-Webb, Briggs-Young and Rabas-Eckels allows to obtain convenient results, with $M A E$ values of $15.3 \%$ to $27.1 \%$, which agrees well with those results given by Camaraza [15].

The specialized literature does not count with reports that suggest the possible maximum executed error with the use of a determined model. In the present study the value of $E_{\text {max }}$ generated with the use of every model for the six studied zones was obtained, by means of the correlation made between the experimental available data and the models selected.

The model developed by Camaraza et al. [14] shows the best $E_{\max }$ index, with $11.5 \%$ and $12.9 \%$ respectively in Zone 1, and 6. On the contrary, the most unfavorable indicators are obtained with the correlations of Griminson and Zukauskas, which provide $E_{\max }$ values of $41.4 \%$ and $38.5 \%$ respectively for Zone 1, increasing to $48.2 \%$ and $43.1 \%$ in Zone 6 . The other models analized in this study provide fairly acceptable adjustments of correlation. The early elements allows

\begin{tabular}{|c|c|c|c|c|c|}
\hline \multicolumn{6}{|c|}{ Valid for $0.4 \leq S_{\mathcal{J}} S_{L} \leq 1 ; 19 \leq d_{e} \leq 50 \mathrm{~mm}$ and $1.3 \leq e_{a} \leq 3.5 \mathrm{~mm}$} \\
\hline Zone & Validity range & Deviation & Zone & e Validity range & Deviation \\
\hline \multirow{5}{*}{1} & $2.5 \leq h_{a} \leq 4.7$ & MAE $<7.6 \%$ for & \multirow{5}{*}{2} & $2.5 \leq h_{a} \leq 5.1$ & MAE $<6.8 \%$ for \\
\hline & $0 \leq \bar{V}_{v} \leq 5.4$ & $89.9 \%$ of the data & & $0 \leq \bar{V}_{v} \leq 10.1$ & $88.1 \%$ of the data \\
\hline & $0 \leq V_{0} \leq 10$ & \multirow{3}{*}{$\begin{array}{c}E_{\max }<11.5 \% \\
N=79\end{array}$} & & $0 \leq V_{0} \leq 28.2$ & $3 \%$ \\
\hline & $15 \leq T_{T B S} \leq 18$ & & & $15 \leq T_{T B S} \leq 24$ & 5 \\
\hline & $115 \leq \mathrm{F} \leq 194$ & & & $115 \leq F \leq 254$ & \\
\hline \multirow{4}{*}{3} & $2.5 \leq h_{a} \leq 5.1$ & $\mathrm{MAE}<5.9 \%$ for & \multirow{4}{*}{4} & $2.5 \leq h_{a} \leq 6.4$ & MAE \\
\hline & $0 \leq V_{v} \leq 16.2$ & $87.3 \%$ of the data & & $0 \leq V_{v} \leq 24.1$ & $88.4 \%$ \\
\hline & $0 \leq V_{0} \leq 41.4$ & \multirow{2}{*}{$\begin{array}{c}E_{\max }<11.2 \% \\
N=192\end{array}$} & & $0 \leq V_{0} \leq 65.6$ & $\%$ \\
\hline & $15 \leq T_{T B S} \leq 30$ & & & $15 \leq T_{T B S} \leq 35$ & \\
\hline \multirow{5}{*}{5} & $\begin{array}{l}115 \leq \mathrm{F} \leq 315 \\
25<h_{0}<79\end{array}$ & MAE & & $\begin{array}{l}115 \leq F \leq 354 \\
25<h_{0}<79\end{array}$ & MAl \\
\hline & $0 \leq V_{v} \leq 38.2$ & $89.7 \%$ & \multirow{4}{*}{6} & $0 \leq V_{v} \leq 45$ & $90.5 \%$ of the data \\
\hline & $0 \leq V_{0} \leq 88.4$ & $E_{\max }$ & & $0 \leq V_{0} \leq 100$ & \\
\hline & $15 \leq T_{T B S} \leq 40$ & $\begin{array}{l}\max x=28.0 \% \\
N=282\end{array}$ & & $15 \leq T_{T B S} \leq 43$ & $\begin{array}{l}\max ^{2} \times 12.9 \% \\
N=368\end{array}$ \\
\hline & $115 \leq F \leq 354$ & & & $\leq 394$ & \\
\hline
\end{tabular}
affirming that the proposed model (Eq. (3)) constitutes a scientific novelty.

Table 2. Correlation of the first range of values with Eq. (1) 

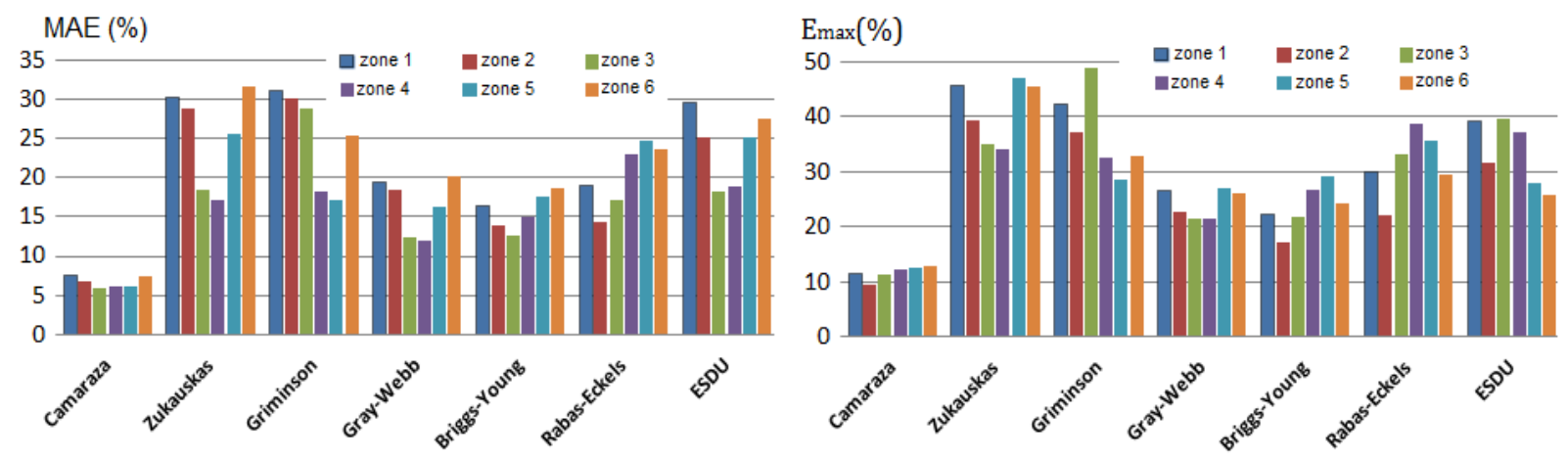

Figure 1. MAE and $E_{\max }$ values obtained in the correlation data with other models for $\left(0.4 \leq S_{T} / S_{L} \leq 1\right)$

Table 3. Correlation of the second range of values with Eq. (1)

\begin{tabular}{|c|c|c|c|c|c|}
\hline \multicolumn{6}{|c|}{ Valid for $1<S_{T} / S_{L} \leq 2 ; 19 \leq d_{e} \leq 50 \mathrm{~mm}$ and $1.3 \leq e_{a} \leq 3.5 \mathrm{~mm}$} \\
\hline Zone & Validity range & Deviation & Zone & Validity range & Deviation \\
\hline \multirow{5}{*}{1} & $2.5 \leq h_{a} \leq 4.7$ & $M A E<6.5 \%$ for & & $2.5 \leq h_{a} \leq 5.1$ & $M A E<7.1 \%$ for \\
\hline & $0 \leq V_{v} \leq 5.4$ & $89.4 \%$ of the data & & $0 \leq V_{v} \leq 10.1$ & $88.3 \%$ of \\
\hline & $0 \leq V_{0} \leq 10$ & \multirow{3}{*}{$\begin{array}{c}E_{\max }<11.8 \% \\
N=82\end{array}$} & & $0 \leq V_{0} \leq 28.2$ & \\
\hline & $15 \leq T_{T B S} \leq 18$ & & & $15 \leq T_{T B S} \leq 24$ & \\
\hline & $11 \overline{5} \leq F \leq 194$ & & & $11 \overline{5} \leq F \leq 254$ & \\
\hline \multirow{5}{*}{3} & $2.5 \leq h_{a} \leq 5.1$ & MAE $<$ & \multirow{5}{*}{4} & $2.5 \leq h_{a} \leq 6.4$ & $M A$ \\
\hline & $0 \leq V_{v} \leq 16.2$ & $87.6 \%$ of $\mathrm{tl}$ & & $0 \leq V_{v} \leq 24.1$ & $90.1 \%$ \\
\hline & $0 \leq V_{0} \leq 41.4$ & & & $0 \leq V_{0 \leq 65.6}$ & \\
\hline & $15 \leq T_{T B S} \leq 30$ & $.5 \%$ & & $15 \leq T_{T B S} \leq 35$ & $\begin{array}{c}E_{\max }<10.9 \% \\
N=302\end{array}$ \\
\hline & $\leq F \leq 315$ & & & $<F<354$ & \\
\hline \multirow{5}{*}{5} & $2.5 \leq h_{a} \leq 7.9$ & $M A E<6.2 \%$ for & \multirow{5}{*}{6} & $2.5 \leq h_{a} \leq 7.9$ & $M A E$ \\
\hline & $0 \leq \bar{V}_{v} \leq 38.2$ & $89.9 \%$ of the data & & $0 \leq V_{v} \leq 45$ & $90.6 \%$ of the dat \\
\hline & $0 \leq V_{0} \leq 88.4$ & & & $0 \leq V_{0} \leq 100$ & \\
\hline & $15 \leq T_{T B S} \leq 40$ & $E_{\max }<11.3 \%$ & & $15 \leq T_{T B S} \leq 43$ & $\begin{array}{c}\boldsymbol{L} \max x \\
N=1.0 \%\end{array}$ \\
\hline & $115 \leq F \leq 354$ & & & $115 \leq F \leq 394$ & \\
\hline
\end{tabular}
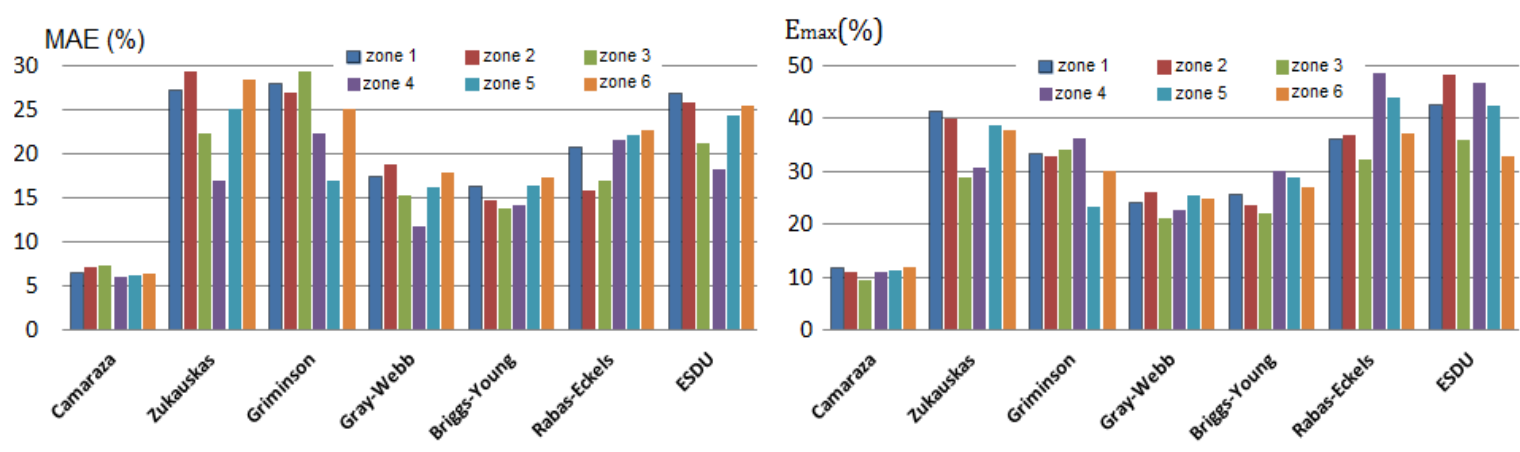

Figure 2. MAE and $\mathrm{E}_{\max }$ values obtained in the correlation data with other models for $\left(1<S_{T} / S_{L} \leq 2\right)$

\section{INTERNAL FLOW}

\subsection{Heat transfer coefficient $\alpha_{T}$}

The combination of the differential equations of the velocity profile and temperature distribution, and their subsequent homogenization by means of gamma functions, allowed to obtain a theoretical solution for the determination of the $\alpha_{\mathrm{T}}$ coefficient inside vertical tubes. The developed expression is given by Medina et al. [16]:

$$
N u_{V e r t}=0.943 \cdot \sqrt[4]{d_{i}^{3} \frac{\sin \varphi \cdot g \cdot\left(\rho_{L}-\rho_{V}\right) \cdot r_{L V}}{v_{L} \cdot \lambda_{L} \cdot\left(T_{s a t}-T_{P}\right)}}
$$

where: $d_{i}$ is the equivalent inner tube diameter, in $\mathrm{m} ; g$ is the gravitational acceleration, in $\mathrm{m} / \mathrm{s}^{2} ; \rho_{L}$ is the liquid density, in $\mathrm{kg} / \mathrm{m}^{3} ; \rho_{V}$ is the steam density, in $\mathrm{kg} / \mathrm{m}^{3} ; r_{L V}$ is the latent heat of vaporization, in $\mathrm{kJ} / \mathrm{kg} ; v_{L}$ is the liquid kinematic viscosity, in $\mathrm{m}^{2} / \mathrm{s} ; \lambda_{L}$ is the fluid thermal conductivity, in $\mathrm{W} /\left(\mathrm{m} \cdot{ }^{\circ} \mathrm{C}\right) ; T_{\text {sat }}$ is the steam saturation temperature, in ${ }^{\circ} \mathrm{C}$ and $T_{P}$ is the mean wall temperature, in ${ }^{\circ} \mathrm{C}$.

Subsequently, [17], the simultaneous solution of the differential equations of energy, momentum, continuity and conductivity was demonstrated, using the function of Tijonov (infinite line) as a weak substitute variable and linear discretization of a finite element one-dimensional three nodes. The definitive solution is reduced to the use of two dimensionless groups, whose combination allows to determine the $\alpha_{T}$ coefficient for any orientation of the tubes. This element constitutes a scientific novelty, as no background of a similar method is found in the literature. 
The analytical solution developed uses the dimensionless velocity criteria and the Crosser number. Through these two criteria, the intervals of applicability of the proposed methodology are established based on the orientation of the ducts, which was subsequently adjusted and correlated with 1192 experimental data reported by 20 researchers. The proposed model yields 11.8 percent of average deviation for horizontal tubes and 13.0 percent for inclined and vertical tubes. The formulation obtained is given and discussed [17]:

$$
\text { Adimensional velocity } J_{g}=\frac{x G}{\sqrt{g d_{i} \rho_{V}\left(\rho_{L}-\rho_{V}\right)}}
$$

$$
\text { Crosser number } Z=\left(\frac{1-x}{x}\right)^{0.8} \operatorname{Pr}_{L}^{0.4}
$$

For vertical and inclined tubes

$$
\text { Interval } 1 J_{g} \geq \frac{1}{2.37 Z+0.728}
$$

$$
\begin{gathered}
\text { Interval } 20.927 e^{\left(-0.0868 Z^{-1.165}\right)}<J_{g}<\frac{1}{2.37 Z+0.728} \\
\text { Interval } 3 J_{g} \leq 0.927 e^{\left(-0.0868 Z^{-1.165}\right)}
\end{gathered}
$$

\section{For horizontal tubes}

$$
\begin{aligned}
& \text { Interval } 1 J_{g} \leq 0.979(Z+0.262)^{-0.618} \\
& \text { Interval } 1 J_{g}>0.979(Z+0.262)^{-0.618}
\end{aligned}
$$

In Eq. (6) to (12), $P r_{L}$ is the Prandtl number for single-phase; $x$ is the thermodynamic vapor quality; $G$ is the mass flux, in $\mathrm{kg} /\left(\mathrm{m}^{2} \mathrm{~s}\right)$.

The proposed expression for the determination of the heat transfer coefficient by condensation inside horizontal tubes is given by Camaraza-Medina et al. [18]:

$$
N u_{T}=N u_{L} \cdot\left\{4.9 x^{0.9}\left[(1-x)^{2}+\frac{(1-x)^{0.1}}{P r^{0.37}}\right]\right\}^{0.8}
$$

In Eq. (13) $\operatorname{Pr}$ is the reduced pressure. The mathematical deduction of the Eq. (13) and the elements associated are provided by Camaraza-Medina et al. [17].

For the determination of $\mathrm{Nu}_{\mathrm{L}}$, in the literature the use of Dittus-Boelter expression is a generalized criterion, however, recently the author showed that the correlation index could be improved by using a model derived from the Prandtl analogy, which is described as [19]:

$$
\begin{gathered}
N u_{L}=\frac{\left(R e_{L}-10^{M}\right) \cdot P r_{L}}{A \cdot I^{2}-J \cdot I \cdot\left(1-\operatorname{Pr}_{L}^{2 / 3}\right)} \cdot\left(1+\left(\frac{d_{i}}{l}\right)^{2 / 3}\right) \\
\cdot\left(\frac{\mu_{F}}{\mu_{F}}\right)^{0.14}
\end{gathered}
$$

where: $R e_{L}$ is the liquid Reynolds number, $\mu_{F}$ is the Fluid dynamic viscosity at mean fluid temperature, in $a \cdot s ; \mu_{P}$ is the fluid dynamic viscosity at wall temperature, in $\mathrm{Pa} \cdot s ; l$ is the length of the tube, in $\mathrm{m}$. The mathematical deduction of the Eq. (14) is given by Camaraza-Medina et al. [20], while the constants used are summarized in Table 4.
Table 4. Values of the constants used in Eq. (14)

\begin{tabular}{lcc}
\hline & $\mathbf{2 . 3} \cdot \mathbf{1 0}^{\mathbf{3}}<\boldsymbol{R e}<\mathbf{1} \cdot \mathbf{1 0}^{\mathbf{4}}$ & $\mathbf{1 \cdot \mathbf { 1 0 } ^ { \mathbf { 4 } } \leq \boldsymbol { R e } \leq \mathbf { 1 } \cdot \mathbf { 1 0 } ^ { \mathbf { 4 } }}$ \\
\hline$A$ & 75.4 & 91.4 \\
$I$ & $\log \left(R e_{L}^{0.56} / 3.196\right)$ & \\
$J$ & 104 & 116.7 \\
$M-0.027[\log R e]^{2}+0.2 \log R e+2.63$ & 0 \\
\hline
\end{tabular}

Additional tests carried out allowed us to conclude that the combination of Eqns. (5) and (13) depending on the work zones, offers a better adjustment to the experimental values available for vertical and inclined tubes. This combination was developed is given by Camaraza-Medina et al. [18]:

$$
\text { Interval } 1 \mathrm{Nu}=N u_{\text {Vert }}
$$

$$
\begin{gathered}
\text { Interval } 2 N u=\sqrt{\left(N u_{T}\right)^{2}+\left(N u_{\text {Vert }}\right)^{2}} \\
\text { Interval } N u=N u_{\text {Vert }}
\end{gathered}
$$

In Eq. (16), if $R e_{V}<3.5 \cdot 10^{4}$, then $N u_{V e r t}=0$. Table 5 provides a detailed summary of parameters range that shows a satisfactory fit with Eqns. (15) to (17).

Table 5. Summary of the validity range for Eq. (15) to (17)

\begin{tabular}{cc}
\hline Parameter & Range \\
\hline & Water, R-22, R-32, R-113, R-123, R-125, R-134a, R- \\
Fluids & 142b, R-404a, R-410a, R-502, R-507, isobutene, \\
& propylene, propane, benzene, ethanol, methanol, \\
& toluene and dowtherm 209. \\
$d_{i}(\mathrm{~mm})$ & $2-50$ \\
$G\left(\mathrm{~kg} / \mathrm{m}^{2} \mathrm{~s}\right)$ & $4-850$ \\
$\operatorname{Pr}_{L}$ & $1-20$ \\
$Z$ & $0.005-20$ \\
$\operatorname{Re}_{L}$ & $60-84830$ \\
$\operatorname{Re}_{V}$ & $8210-523980$ \\
$x$ & $0.01-1$ \\
$p_{r}$ & $0.0008-0.91$ \\
Tube & Horizontal, vertical and inclined \\
orientation & $0.6-20$ \\
$J_{g}$ &
\end{tabular}

In Tables 6 and 7, the validity range of Eqns. (15) to (17) is fragmented into four intervals, while in Figures 3 and 4 the values of $M A E$ and $E_{\max }$ obtained in the correlation developed between available experimental data and selected models are given in graphical form [15].

For vertical and inclined tubes only the Shah model is used for comparison, since the remaining ones are only valid for horizontal tubes. An analysis of Figures 3 and 4 shows that the Chato's formulation generates a low adjustment of average values, which are between 28 and 43 percent, with a maximum error rate close to 60 percent in the four zones.

For horizontal tubes, the Chato's Equation provides an MAE values in the range of 17 to 24 percent, with the best fit in zone 3 , in which the values of $p_{r}$ and $d_{i}$ agree very well with the precepts under which the Chato model was developed.

In Tables 8 and 9, the validity range of the Eq. (14) is divided into six intervals. In Figures 5 and 6 the values of $M A E$ and $E_{\max }$ obtained in the correlation developed between available experimental data and selected models are given in graphical form [15].

For transition zone $2.4 \times 10^{3} \leq R e<10^{4}$ (see Figure 5), the most unfavorable indicators are obtained using the models 
of Dittus-Boelter and Mijeev, which provide $M A E$ values respectively of $38.4 \%$ and $36.1 \%$ for $64.5 \%$ and $68.1 \%$ of the experimental data, respectively. Hausen's model allows to obtain convenient results, with $M A E$ values of $19.3 \%$ in $75.1 \%$ of the examined data, which agrees well with those results given by Su An and Kim [21].
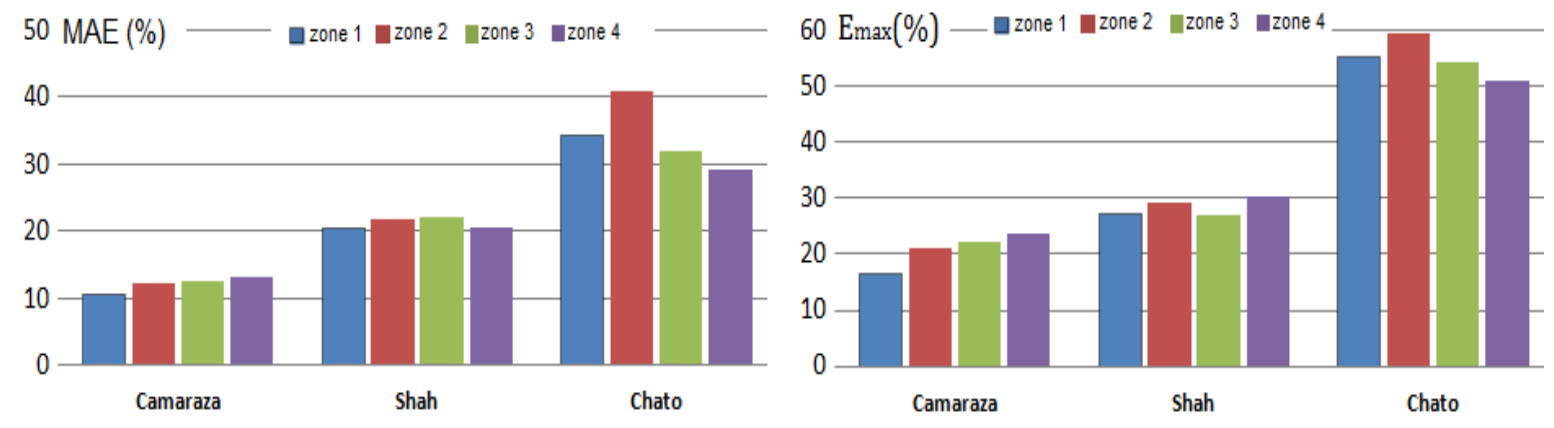

Figure 3. $M A E$ and $E_{\max }$ values obtained in the correlation data with other models for vertical and inclined tubes

Table 6. Correlation of experimental values with respect to Eqns. (15) to (17)

\begin{tabular}{|c|c|c|c|c|c|}
\hline \multicolumn{6}{|c|}{ Vertical and inclined tubes } \\
\hline Zone & Validity range & Deviation & Zon & Validity range & Deviation \\
\hline \multirow{5}{*}{1} & $\operatorname{Re}_{L} \leq 9.8 \cdot 10^{3}$ & $M A E<10.6 \%$ for & \multirow{5}{*}{2} & $R e_{L} \leq 59 \cdot 10^{3}$ & $M A E<12.2 \%$ for \\
\hline & $R e_{v} \leq 1.7 \cdot 10^{5}$ & $89.3 \%$ of the data & & $R e_{v} \leq 3.33 \cdot 10^{5}$ & $85.4 \%$ of the data \\
\hline & $2 \leq d_{i} \leq 8.0$ & \multirow{3}{*}{$E_{\max }<16.6 \%$} & & $2 \leq d_{i} \leq 19.3$ & \\
\hline & $3 \leq G \leq 264$ & & & $3 \leq G \leq 468$ & $E_{\max }<21.1 \%$ \\
\hline & $0.01 \leq x \leq 0.99$ & & & $\begin{array}{c}0.01 \leq x \leq 0.99 \\
n \leq 025\end{array}$ & $N=479$ \\
\hline \multirow{6}{*}{3} & $\operatorname{Re}_{L} \leq 59 \cdot 10^{3}$ & $M A E<12.4 \%$ for & & $\operatorname{Re}_{L} \leq 59 \cdot 10^{3}$ & $M A E<13 \%$ for \\
\hline & $R e_{v} \leq 3.33 \cdot 10^{5}$ & $82.9 \%$ of the data & \multirow{5}{*}{4} & $R e_{v} \leq 3.33 \cdot 10^{5}$ & $84.1 \%$ of the data \\
\hline & $2 \leq d_{i} \leq 30$ & & & $2 \leq d_{i} \leq 47.5$ & \\
\hline & $3 \leq G \leq 538$ & $E_{\max }<22.4 \%$ & & $3 \leq G \leq 598$ & $E_{\max }<23.4 \%$ \\
\hline & $0.01 \leq x \leq 0.99$ & $N=542$ & & $0.01 \leq x \leq 0.99$ & $N=584$ \\
\hline & $p_{r} \leq 0.44$ & & & $p_{r} \leq 0.66$ & \\
\hline
\end{tabular}
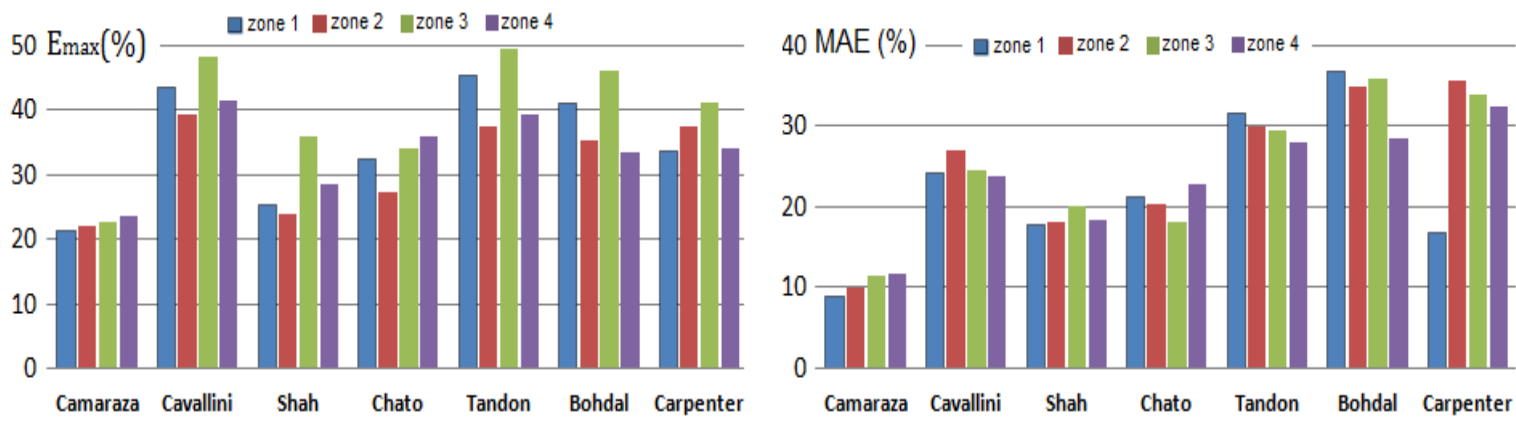

Figure 4. $M A E$ and $E_{\max }$ values obtained in the correlation data with other models for horizontal tubes

Table 7. Correlation of experimental values with respect to Eqns. (15) to (17)

\begin{tabular}{|c|c|c|c|c|c|}
\hline \multicolumn{6}{|c|}{ Horizontal tubes } \\
\hline Zone & Validity range & Deviation & Zone & Validity range & Deviation \\
\hline \multirow{6}{*}{1} & $R e_{L} \leq 6.4 \cdot 10^{4}$ & $M A E<8.9 \%$ for & \multirow{5}{*}{2} & $R e_{L} \leq 7.0 \cdot 10^{4}$ & $M A E<10 \%$ for \\
\hline & $R e_{v} \leq 2.1 \cdot 10^{5}$ & $83.3 \%$ of the data & & $R e_{v} \leq 4.8 \cdot 10^{5}$ & $81.2 \%$ of the data \\
\hline & $2 \leq \mathrm{d}_{\mathrm{i}} \leq 8.0$ & & & $2 \leq d_{i} \leq 8.0$ & \multirow{4}{*}{$\begin{array}{c}E_{\max }<22.2 \% \\
N=436\end{array}$} \\
\hline & $38 \leq \mathrm{G} \leq 300$ & $E_{\max }<21.3 \%$ & & $38 \leq \mathrm{G} \leq 600$ & \\
\hline & $0.01 \leq x \leq 0.99$ & $N=265$ & & $0.01 \leq x \leq 0.99$ & \\
\hline & $p_{r} \leq 0.1$ & & & $p_{r} \leq 0.3$ & \\
\hline \multirow{4}{*}{3} & $R e_{L} \leq 8.5 \cdot 10^{4}$ & $M A E<11.5 \%$ for & \multirow{4}{*}{4} & $R e_{L} \leq 8.5 \cdot 10^{4}$ & $M A E<11.8 \%$ for \\
\hline & $R e_{v} \leq 5.9 \cdot 10^{5}$ & $81.9 \%$ of the data & & $R e_{v} \leq 6 \cdot 10^{5}$ & $84.3 \%$ of the data \\
\hline & $2 \leq \mathrm{d}_{\mathrm{i}} \leq 18.9$ & & & $2 \leq \mathrm{d}_{\mathrm{i}} \leq 49$ & \\
\hline & $\begin{array}{c}0.01 \leq x \leq 0.99 \\
p_{r} \leq 0.5\end{array}$ & 538 & & $\begin{array}{c}0.01 \leq x \leq 0.99 \\
p_{r} \leq 0.91\end{array}$ & $N=608$ \\
\hline
\end{tabular}




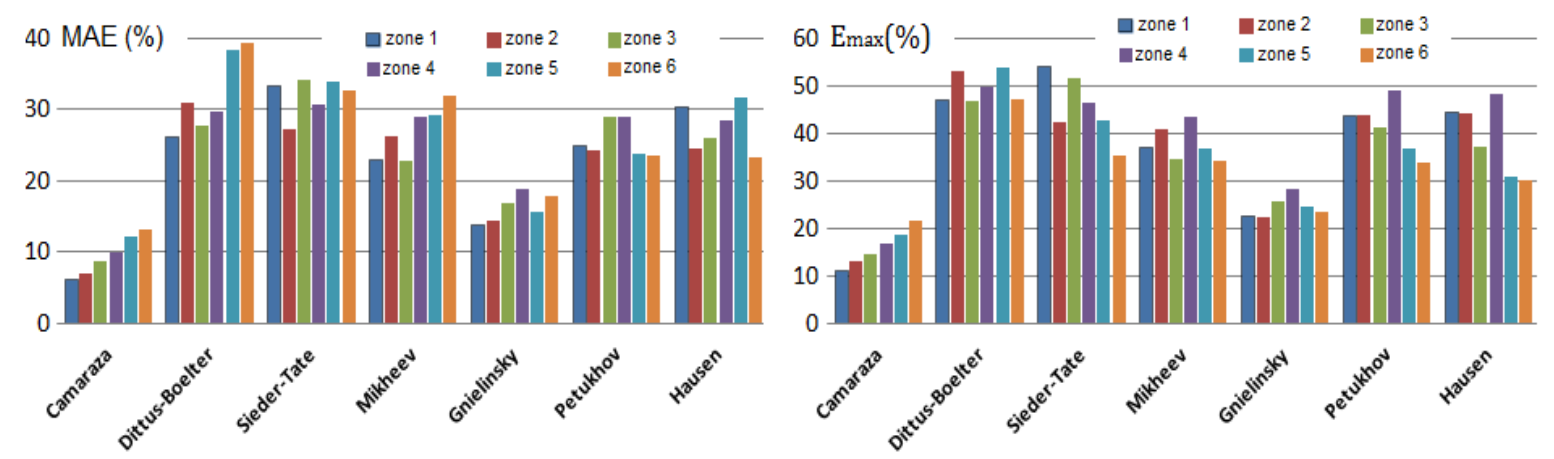

Figure 5. $M A E$ and $E_{\max }$ values obtained in the correlation data with other models for $2.4 \cdot 10^{3} \leq R e<10^{4}$

Table 8. Correlation of the first range of values with Eq. (14)

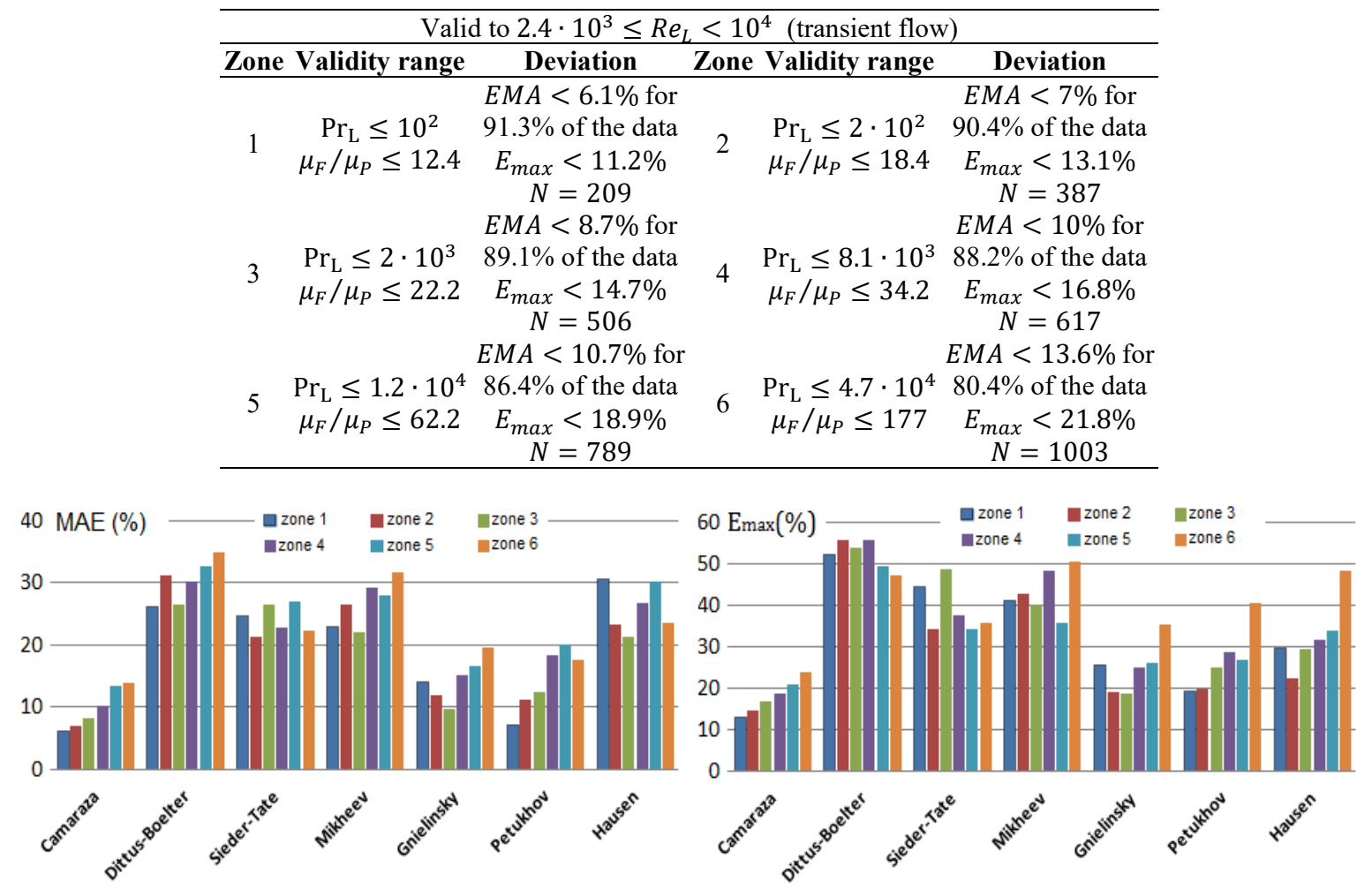

Figure 6. $M A E$ and $E_{\max }$ values obtained in the correlation data with other models for $10^{4}<R e \leq 8.2 \cdot 10^{6}$

Table 9. Correlation of the second range of values with Eq. (14)

\begin{tabular}{|c|c|c|c|c|c|}
\hline \multicolumn{6}{|c|}{ Valid to $10^{4}<R e_{L} \leq 8.2 \cdot 10^{6}$ (Turbulent flow) } \\
\hline Zone & y range & Deviation & Zone & Validity range & De \\
\hline 1 & $\begin{array}{c}\operatorname{Pr}_{\mathrm{L}} \leq 10^{2} \\
\mu_{F} / \mu_{P} \leq 12.4\end{array}$ & $\begin{array}{c}E M A<13.1 \% \text { for } \\
89.4 \% \text { of the data } \\
E_{\max }<12.8 \% \\
N=419\end{array}$ & 2 & $\begin{array}{c}\operatorname{Pr}_{\mathrm{L}} \leq 2 \cdot 10^{2} \\
\mu_{F} / \mu_{P} \leq 18.4\end{array}$ & $\begin{array}{r}E M A<1 \\
88.3 \% \text { of } \\
E_{\max }< \\
N=\end{array}$ \\
\hline 3 & $\begin{array}{l}2 \cdot 10^{3} \\
\leq 22.2\end{array}$ & $\begin{array}{c}E M A<8.3 \% \text { for } \\
86.1 \% \text { of the data } \\
E_{\max }<16.9 \% \\
N=1127\end{array}$ & 4 & $\begin{array}{c}\operatorname{Pr}_{\mathrm{L}} \leq 8.1 \cdot 10^{3} \\
\mu_{F} / \mu_{P} \leq 34.2\end{array}$ & $\begin{array}{r}E M A \\
85.3 \% \\
E_{\max } \\
N\end{array}$ \\
\hline 5 & $\begin{array}{c}\operatorname{Pr}_{\mathrm{L}} \leq 1.2 \cdot 10^{4} \\
\mu_{F} / \mu_{P} \leq 62.2\end{array}$ & $\begin{array}{c}E M A<11.3 \% \text { for } \\
83.1 \% \text { of the data } \\
E_{\max }<20.9 \% \\
N=1715\end{array}$ & 6 & $\begin{array}{c}\operatorname{Pr}_{\mathrm{L}} \leq 4.7 \cdot 10^{4} \\
\mu_{F} / \mu_{P} \leq 177\end{array}$ & $\begin{array}{c}E M A<14 \% \text { for } \\
80.8 \% \text { of the data } \\
E_{\max }<24.1 \% \\
N=2093\end{array}$ \\
\hline
\end{tabular}

The correlations of Petukhov and Sieder-Tate are not valid in this interval; however, they provide an adequate result, with $M A E$ values of 24.6 and $29.4 \%$ for 72.4 and $70.5 \%$ of the experimental data, respectively; this indicates that they can be used for rapid estimations of the heat transfer coefficients in the transition zone, which confirms the recommendations given by Su An and Kim [21].

For turbulent zone $10^{4} \leq R e<8.2 \times 10^{6}$ (see Figure 6), 
the most unfavorable indicators are obtained with the DittusBoelter and Sieder-Tate models. The first provides $M A E$ values of $21.6 \%$ and $39.3 \%$ for $74.2 \%$ and $66.7 \%$ of the data, for Zones 1 and 6, respectively. The second model shows $M A E$ values of $14.3 \%$ and $36.5 \%$ for $80.9 \%$ and $72.4 \%$ of the experimental data, for Zones 1 and 6, respectively.

The models by Mijeev and Hausen allow obtaining convenient correlation results. Hausen's model provides $M A E$ values of $9.8 \%$ and $20.4 \%$ for $85.2 \%$ and $74.2 \%$ of the experimental data, for Zones 1 and 6, respectively. The model by Mijeev shows $M A E$ values of $15.5 \%$ and $32.8 \%$ for $77.6 \%$ and $70.2 \%$ of the experimental data, for Zones 1 and 6 , respectively.

\section{CONCLUSIONS}

The correlation and adjustment of available experimental data facilitated the development of new models that allow reducing the uncertainty in the determination of the internal and external film coefficients, being established a comparison between the proposal and other existing relationships in the literature, which results in a lower dispersion margin for the models described in this work.

The average correlation error in the determination of the $\alpha_{L}$ and $\alpha_{T}$ coefficients is reduced for external and internal flow up to 6.9 and 13 percent respectively. Regarding the elements of study presented, there is no evidence of similar expressions in the available and known literature, which is why they are considered a scientific novelty.

\section{ACKNOWLEDGMENT}

The author is very grateful for the help provided by Professor S. Thomson, from the Department of Mathematics, Massachusetts Institute of Technology, USA and Dr. Moustafa Zeki Yilmazouglu, from the Department of Mechanical Engineering, Gazi University, Turkey.

\section{REFERENCES}

[1] Huang, X., Chen, L., Kong, Y., Yang, L., Du, X. (2018). Effects of geometric structures of air deflectors on thermo-flow performances of air-cooled condenser. International Journal of heat and Mass Transfer, 118: 1020-1032.

https://doi.org/10.1016/j.ijheatmasstransfer.2017.11.071

[2] ECIAZ. (2019). Datos técnicos e ingeniería básica para el proyecto de instalación de centrales eléctricas de biomasa en el quinquenio 2020-2025, (ECIAZ, SA.), La Habana.

[3] INRH. (2020). Boletín de Análisis de lluvias, embalses, acuíferos y costo del agua, Dirección de Uso Racional del Agua, INRH, La Habana. http://www.inrh.gob.cu/032020.htm, accessed on May 17, 2020.

[4] IDEA. (2020). World Energy Resources 2020, Oklahoma University State, 21-23.

[5] Owen, M., Kröger, D.V. (2017). A numerical investigation of vapor flow in large air-cooled condensers. Applied Thermal Engineering, 127: 157-164. http://dx.doi.org/10.1016/j.applthermaleng.2017.08.026

[6] Deng, H., Liu, J., Zheng, W. (2019). Analysis and comparison on condensation performance of core tubes in air-cooling condenser. International Journal of Heat and Mass Transfer, 135: 717-731. https://doi.org/10.1016/j.ijheatmasstransfer.2019.02.011

[7] Yuan, W., Sun, F., Zhao, Y., Chen, X., Li, Y., Lyu, X. (2020). Numerical study on the influence mechanism of crosswind on frozen phenomena in a direct air-cooled system. $\quad$ Energies, 3831. https://doi.org/10.3390/en13153831

[8] Li, J., Bai, Y., Li, B. (2018). Operation of air cooled condensers for optimized back pressure at ambient wind. Applied Thermal Engineering, 128: 1340-1350. https://doi.org/10.1016/j.applthermaleng.2017.09.122

[9] Deng, H., Liu, J. (2019). Performance prediction of finned air-cooled condenser using a conjugate heattransfer model. Applied Thermal Engineering, 150: 386397.

https://doi.org/10.1016/j.applthermaleng.2019.01.012

[10] Jin, R., Yang, X., Yang, L., Du, X., Yang, Y. (2018). Square array of air-cooled condensers to improve thermo-flow performances under windy conditions. International Journal of heat and Mass Transfer, 127: 717-729.

https://doi.org/10.1016/j.ijheatmasstransfer.2018.06.135

[11] Loganathan, P., Dhivya, M. (2018). Thermal and mass diffusive studies on a moving cylinder entrenched in a porous medium. Latin American Applied Research, 48(2): 119-124.

[12] Gama, R.M.S. (2019). Non-linear problem arising from the description of the wave propagation in linear elastic rods. Latin American Applied Research, 49(1): 61-63.

[13] Cano-Moreno, J.D., Cabanellas-Becerra, J.M. (2019). Experimental validation of an escalator simulation model. Latin American Applied Research, 49(3): 187-192.

[14] Camaraza-Medina, Y., Rubio-Gonzales, A.M., CruzFonticiella, O.M., Garcia-Morales, O.F., Vizcon-Toledo, R., Quiza-Sardiñas, R. (2018). Simplified analysis of heat transfer through a finned tube bundle in air-cooledcondenser-second assessment. Mathematical Modelling of Engineering Problems, 5(4): 365-372. http://doi.org/10.18280/mmep.050413

[15] Camaraza, Y. (2017). Introducción a la termotransferencia. Editorial Universitaria, La Habana.

[16] Medina, Y.C., Khandy, N.H., Carlson, K.M., Fonticiella, O.M.C., Morales, O.F.C. (2018). Mathematical modeling of two-phase media heat transfer coefficient in air-cooled condenser systems. International Journal of Heat and Technology, 36(1): 319-324. https://doi.org/10.18280/ijht.360142

[17] Camaraza-Medina, Y., Hernandez-Guerrero, A., Luviano-Ortiz, J.L., Cruz-Fonticiella, O.M., GarcíaMorales, O.F. (2019). Mathematical deduction of a new model for calculation of heat transfer by condensation inside pipes. International Journal of Heat and Mass Transfer, 141: 180-190. https://doi.org/10.1016/j.ijheatmasstransfer.2019.06.076

[18] Camaraza-Medina, Y., Hernández-Guerrero, A, Luviano-Ortiz, J.L, Mortensen-Carlson, K, CruzFonticiela, O.M., García-Morales, O.F. (2019). New model for heat transfer calculation during film condensation inside pipes. International Journal of Heat and Mass Transfer, 128: 344-353. https://doi.org/10.1016/j.ijheatmasstransfer.2018.09.012

[19] Camaraza-Medina, Y., Cruz-Fonticiella, O.M., García- 
Morales, O.F. (2019). New model for heat transfer calculation during fluid flow in single phase inside pipes. Thermal Science and Engineering Progress, 11: 162-166. https://doi.org/10.1016/j.tsep.2019.03.014

[20] Camaraza-Medina, Y., Mortensen-Carlson, K., Guha, P., Rubio-Gonzales, A.M., Cruz-Fonticiela O.M., GarcíaMorales, O.F. (2019). Suggested model for heat transfer calculation during fluid flow in single phase inside pipes (II). International Journal of Heat and Technology, 37(1): 257-266. https://doi.org/10.18280/ijht.370131

[21] An, C.S., Kim, M.H. (2018). Thermo-hydraulic analysis of multi-row cross-flow heat exchangers. International Journal of Heat and Mass Transfer, 120: 534-539. https://doi.org/10.1016/j.jheatmasstransfer.2017.12.088 